\title{
LA HISPANIDAD DE LOS OTROS: EN TORNO A LEOPOLdO Alas "CLARÍN" Y LA LENGUA CATALANA
}

\author{
Mariano Saba \\ Universidad de Buenos Aires
}

\begin{abstract}
Resumen: Las relaciones entre Leopoldo Alas y el campo intelectual catalán de fines de siglo XIX revelan ciertos mecanismos recurrentes del escritor ovetense en torno al nacionalismo de su época. Algunas declaraciones de Clarín sobre la lengua catalana —entre la intimidad epistolar y sus abiertos postulados críticos-- permiten pensar las contradicciones del encuadre liberal con relación al concepto de hispani$d a d$, a sus límites y a su defensa.
\end{abstract}

Palabras claves: Campo intelectual; hispanidad; lengua catalana; Leopoldo Alas; nacionalismo.

Recibido: 15 de octubre de 2018

Aprobado: 25 de octubre de 2018

THE HiSPANITY OF THE OTHERS: AROUND LeOPOLdo Alas "CLARÍN" AND THE CATALAN LANGUAGE

Abstract: The relations between Leopoldo Alas and the Catalan intellectual field at the end of the 19th century reveal certain recurrent mechanisms of the writer from Oviedo around the nationalism of his time. Clarín's statements about the Catalan language — between epistolary privacy and its open critical postulates - allow us to think about the contradictions of the liberal framework in relation to the concept of hispanidad, its limits and its defense.

Keywords: Catalan language; hispanity; intellectual field; Leopoldo Alas; nationalism.

\footnotetext{
${ }^{1}$ Mariano Saba es Doctor en Letras por la Facultad de Filosofía y Letras de la Universidad de Buenos Aires (Diploma de Honor). Actualmente se desempeña como Investigador Asistente de CONICET con su estudio sobre "Leopoldo Alas y el nacionalismo español: la crítica clariniana entre la hispanidad y los Modernismos(s)", radicada en el Instituto de Filología y Literaturas Hispánicas "Dr. Amado Alonso" de la Facultad de Filosofía y Letras (UBA). Correo electrónico: marianosaba@gmail.com
} 


\section{La hispanidad de los otros: en torno a Leopoldo Alas "Clarín" y la lengua catalana}

El 23 de enero de 1900, Unamuno escribe una carta dirigida a Luis Ruiz Contreras explicando las resonancias de Kierkegaard que podían encontrarse en Ibsen. Defensor acérrimo del filósofo danés, introductor pionero de su obra en el ámbito castellano, parece quejarse irónicamente de la necesidad de autorización que exigía toda literatura extranjera en su país. Y señala:

Si yo fuese Clarín me soltaba con un artículo diciendo: 'Todavía no sabe nadie en España quién es Kierkegaard y aquí estoy yo, aduanero de las Letras, para ponerle el marchamo' (Unamuno citado en Garcia Blanco 190).

No resulta para nada menor este registro unamuniano de la autoridad ejercida por Leopoldo Alas como pivote de las legitimidades en curso dentro del campo literario español de fines de siglo XIX e inicios del siglo XX. Momento álgido de su contexto histórico, la reciente pérdida de las últimas colonias de ultramar obligaba a la intelectualidad española a producir estrategias de contención política con respecto a la crisis de identidad nacional provocada sobre todo por el declive imperial. Entre los más importantes exponentes críticos del momento, el perfil clariniano resulta fundamental para comprender las características más oblicuas de la radicalización experimentada por el nacionalismo liberal español. Incluso desde un encuadre más abierto que el de la ortodoxia conservadora del neocatolicismo, es insoslayable la postura defensiva de los liberales españoles ante la percepción de amenaza que encarnaba por entonces para el núcleo hispánico no sólo cierta otredad foránea, sino también cualquier gesto emergente de emancipación cultural dentro de los propios límites de la nación. En estas segundas coordenadas cabe situar la tensión identitaria entre la hispanidad castellana y la singularidad efervescente de la cultura catalana de entresiglos.

Tan significativa resulta la cuestión en ese período finisecular, que el propio Unamuno dedicó un artículo a desarrollar su mirada al respecto. Con el título "Sobre el uso de la lengua catalana", publicó en el Diario Moderno (hacia mayo de 1896) sus consideraciones en torno a la 
pertinencia del uso de las lenguas peninsulares para la plena existencia de sus respectivas culturas. Explica así:

El primer deber de sinceridad es hablar y escribir cada uno, en cuanto le sea posible, en la lengua en que piensa y lengua que piensa a la vez, en la que es carne de sus ideas.

Hablando y escribiendo cada cual su lengua nos hemos de entender mejor al cabo, porque nos entenderemos en armonía y no en monotonía; en armonía que brota de integración de diferencias cumplida por adaptación selectiva y libre, y no en monotonía de batuta autoritaria (Unamuno 1958a 723, 724).

Fiel a sus ideas en torno a la lengua en general, aquella que concibe con un estatuto demiúrgico inexpugnable, el liberal Unamuno sabe que la nación española necesita de la unidad cultural que el Estado central mantiene desde cierto casticismo hegemónico y es justamente eso lo que rechaza. La univocidad política —en una opinión que data de dos años antes del desastre de Cuba y de la radicalización del nacionalismo hispánico- le parece dañina para la concepción metafísica de una hispanidad múltiple capaz de hallar lo más profundo de su ser intrahistórico en la aceptación integradora de sus opuestos —sean lingüísticos, religiosos o culturales-. Por eso Unamuno insiste en la necesidad de un límite a la cerrazón del castellanocentrismo. Y al respecto señala:

[T]odo castellano de espíritu abierto e inteligencia sesuda y franca debe desear que los catalanes escriban en catalán, porque produciéndose más como ellos son, nos darán más, y obligándonos a esfuerzos para entenderlos, nos arrancarán a las solicitaciones de la pereza mental y del exclusivismo. Sacan más uno de otros dos pueblos autónomos en absoluto libre cambio que sometidos a una unidad centralizadora, vejatoria para uno y otro (Unamuno 1958a 724).

Es notable cómo desde las coordenadas liberales el código económico viene a aglutinar sentidos paralelos entre lo político y lo lingüístico. Esto resuelve no sólo la legitimidad del uso "regional" de la lengua en su intercambio con el resto de la nación, sino que además define la coherencia con la definición sistémica del laissez faire. En Unamuno, 
este paralelismo suma también cierta resonancia metafísica ligada a su particular noción del lenguaje - y de la literatura — como laboratorio de vida. Es decir, las asociaciones ideológicas de lengua y librecambio no cierran el circuito unamuniano que legitima el uso del catalán; también lo hace su credo poético de que la lengua construye una existencia, dado que a su juicio creer es crear y sólo crea la palabra. Imponer una palabra "otra" - movimiento básico de cualquier nacionalismo expansivo e imperial - sería cohibir —en términos unamunianos - la potencia no sólo expresiva sino existencial de una cultura específica. Por eso refuerza este sentido afirmando que

Si el catalán escribe en castellano, perderá algo de su alma propia, y eso que pierda es precisamente lo que más nos interesa conocer a los no catalanes, porque es lo activo en él y durmiente en nosotros (Unamuno 1958a 725).

¿Por qué resulta tan importante evocar estos planteos en el abordaje de las contradicciones evidenciadas por Leopoldo Alas con respecto a la revitalización cultural de Cataluña? En principio porque el propio artículo de Unamuno porta una dedicatoria significativa que expresa: "A mi amigo Clarín, el crítico más sugestivo de España" (Unamuno 1958a 723). Lejos de tratarse de una casualidad, el final del ensayo unamuniano vuelve a su dedicatario con el objeto de cerrar el círculo y reenviar la discusión - de forma oblicua - al oscilante "casticismo" de su admirado Leopoldo Alas. Porque Unamuno alude en sus conclusiones al límite del escritor ovetense con respecto a la demanda de apertura que él mismo estaba reclamando:

Aseguraba Clarín en una "Revista mínima" que no siente el alma del catalán, alma en que cree y que por eso dice que no sabe catalán. Y es natural, no cabe sentir esa alma sin rasgar primero el vestido en que se envuelve, su lengua. Excitaba Clarín a Oller (...) a que escribiera en castellano, y contestaba muy sesudamente Oller "que era imposible, que no estaría allí todo él". Y yo añado que creo sacarán los lectores castellanos más provecho de Oller escribiendo éste catalán y traduciéndolo, de un modo o de otro, Clarín, que tan excelentes traducciones hace a su modo, que no traduciéndose el mismo Oller al castellano (Unamuno 1958a 728). 
La alusión velada de Unamuno va dirigida claramente a los límites que también le señalara a Alas con relación a su respeto contradictorio por la arqueología casticista y por sus adalides conservadores ${ }^{2}$. Clarín, según Unamuno, parece merodear la trampa trágica de todo liberalismo finisecular: el criterio de absoluta libertad para el desarrollo de las particularidades culturales fricciona rápidamente con el sostenimiento de las exigencias centralizadoras del propio nacionalismo contenedor que vendría a garantizar un marco de identidad para el territorio generalizado del Estado. El "aduanero de las letras", tal como calificaba Unamuno a Clarín, resulta así literalidad pura del mote metafórico: un nexo necesario que contradice en sus términos al propio sistema que lo necesita. La aduana viene a imponer una regulación dentro de los postulados del librecambio ya sea que se trate de bienes materiales o de capitales intelectuales (lingüísticos y hasta literarios), el aduanero aplica un límite allí mismo donde se pregona el libre fluir. Sin embargo - y esa es la característica "trágica" de liberalismo europeo de fin de siglo ${ }^{4}$ - impone una regla para garantizar paradójicamente la libertad del juego. En el juego de legitimidades sobre la lengua catalana, el "aduanero" Clarín diseña una frontera sinuosa cuya línea demarcatoria oscila entre la fascinación por la modernidad intelectual de Barcelona y la mirada castellanocéntrica que poseía como máxima autoridad de legitimación en el campo crítico español.

Por todo esto, no es casual que Unamuno refiera esa obstinada insistencia de Alas sobre Narcís Oller para persuadirlo de volcar su

\footnotetext{
${ }^{2}$ Tras la reseña clariniana sobre Tres ensayos, Unamuno escribe una carta elocuente a Clarín donde el propio ejercicio apologético e intimista le permite - en tercera persona, como si se objetivara a sí mismo - recordar cierta sátira suya de Menéndez y Pelayo y confesar por escrito aquella muestra concreta de su irónica distancia con la erudición: “¿Y por qué cree usted que Unamuno no se ha metido a crítico? (Y le incitan a que lo haga algunos de la gente nueva, diciéndole que es puesto vacante, $\mathrm{y}$ al decirlo, aluden a usted.) Porque no tiene valor, porque le falta el mismo valor que a usted le falta para decir la verdad de nuestros consagrados; porque, habiendo sido alumno de Don Marcelino y habiendo aprendido no poco de él, no se atreve a decir lo que de él cree (lo suelta en indirectas, como en aquel Joaquín Rodríguez Janssen, que usted mandó no se publicase en La vida literaria)" (Menéndez Pelayo, Unamuno y Palacio Valdés 95).

${ }^{3}$ En relación con este tema, es útil considerar los planteos de Pascale Casanova. En su opinión, la crítica resulta "creadora de valor literario" (38) en tanto posee cierta autoridad debida a su pertenencia nacional. El crítico contribuye "al crecimiento del patrimonio literario de la nación que consagra" (39).

${ }^{4} \mathrm{Al}$ respecto es sumamente interesante considerar el estudio de Raymond Williams (1975) sobre Ibsen y la tragedia liberal.
} 
praxis narrativa al castellano. Resulta sumamente elocuente un rápido recorrido sobre la presión epistolar que ejerció Clarín sobre el novelista catalán. El 27 de junio de 1885, le escribe explicándole que Pereda le ha recomendado "la lectura de las obras catalanas de usted" (Alas 2009 149) y confiesa su desconocimiento de la lengua: "tenía entre mis proyectos de trabajo el de emprender por primera vez en mi vida el estudio del catalán, para poder llegar a saborear su ya célebre Papallona..." (Ibid.). Y luego: "aunque me costara trabajo entender el catalán, que yo no sé por qué me pareció siempre más difícil para mí que una lengua del todo extraña" (Ibid). Y también: "No sé qué tienen para mí el inglés y el catalán que hasta me ponen nervioso" (Ibid).

Sin embargo, la confesa distancia con la lengua catalana no lo exime de postularse como nexo 'diplomático': “de hoy en más seré yo un lector asiduo de las producciones literarias de Cataluña, que tan simpática me es y a la que debo gran parte de lo poco que significo" (Alas 2009 150); o como confirma al final de la carta: "Para mí será una gran satisfacción contribuir a la comunicación constante y amistosa entre literatos castellanos y catalanes como hace tiempo vengo procurándolo respecto de los portugueses" (Ibid). Esta fluctuación entre el señalamiento de la diferencia y el esfuerzo por asimilarla dentro de lo "nacional" español, vuelve a aparecer en las siguientes cartas de Clarín a Oller: el 16 de diciembre de 1885, desde Oviedo, elogia La Papallona y confiesa: “del todo no me gustan más novelistas españoles que Galdós (este, ante todo), Pereda [...] y usted" (Id. 177), pero explica enseguida que el placer se debe a no tener la novela "líneas exóticas" (Ibid.) ¿foráneas? - que pudieran arruinarla.

El 11 de enero de 1886 le agradece el envío de Vilaníu pero se disculpa por el retraso de sus lecturas y refuerza de todos modos su gesto de inclusión canónica abarcadora: "trabaja usted por la gloria de la patria, como Galdós y Pereda" (Alas 2009 179), le escribe en despedida. El 30 de enero de 1887, Alas sigue disculpándose por su deuda "diplomática" aún incumplida, "la de hablar al público de Castilla de los libros de usted con la atención y el detenimiento que merecen" (Id. 206). En plan de resarcimiento, tal vez, Alas le solicita el 12 de diciembre de 1889, una colaboración para La España Moderna y en su 
invitación revela plena conciencia de lo que hasta entonces mantenía como tensión soterrada: "Podría usted escribirlo en catalán, después traducirlo y si usted no quiere decir que escribe el artículo en castellano yo no tendría inconveniente en decir que lo había traducido yo" (Id. 292). Y agrega: "Tengo vivísimos deseos de que Oller sea en Castilla mucho más apreciado de lo que es" (ibíd.). Sin embargo, su intención de acercamiento se torna cada vez más ambigua en lo tocante a sus deseos de efectivizar la recepción crítica del novelista catalán y —al mismo tiempo - de alivianar la desconsideración para con la lengua de sus obras. "La mayor parte de los castellanos, el público grande, jamás podrá leer catalán. Y es absurdo que sea usted más conocido y estimado en Francia que en Castilla" (ibíd.), señala Clarín actualizando con la mención de Francia, la verdadera competencia intelectual europea en el reparto de legitimidades.

En esa línea, el fin de la misiva no puede ser más elocuente: "Por su carta veo que maneja el español perfectamente, ¿por qué no escribe en español también, sin perjuicio de hacerlo en catalán?" (Alas 2009 292.). La última carta que Alas le envía a Oller parece justamente exhibir la negativa final de este último a seguir la "invitación" a producir literatura en español; es 13 de marzo de 1891 y Clarín sigue lamentándose con cierto subtexto de resignación-: "siento que pertenezcamos a literaturas en realidad distintas, por lo cual yo estaría casi siempre hablando al público de usted" (Id. 315).

Más allá de los pocos comentarios que pueden recogerse tal como lo hizo Unamuno, la dilación del abordaje esporádico de la obra de Oller revela en Alas todo un conflicto con respecto a la cultura catalana en general. Y, sin embargo, si bien algunas zonas de su epistolario - como las ya citadas - parecen evidenciar rápidamente una actitud castellanocéntrica ligada al nacionalismo español más ortodoxo. $\mathrm{Su}$ operatoria pública como crítico decisivo del canon moderno suele paradójicamente situarlo en la apertura integradora que le demandaba el autor de Niebla. De hecho, pocos años después del intercambio con Oller, en julio de 1889, Alas publica su comentario sobre El año pasado (1888), volumen que reunía diversos artículos críticos de Josep Yxart. Recogida luego en Ensayos y revistas — de 1892 - la reseña de Clarín 
sobre los trabajos de su colega catalán sirven también para calibrar las paradojas en que se vio inmerso el nacionalismo liberal ante la pérdida de la hegemonía política y cultural de España hacia fines del siglo XIX. Son sinceros e inequívocos los elogios que emite Clarín con respecto a la modernidad de los intelectuales barceloneses en el contexto de declive que el campo crítico castellano venía transitando desde varias décadas atrás.

Alas sostiene lo que afirmará una y otra vez: la crítica catalana de su tiempo resulta clave modélica para el salvataje de la anquilosada praxis madrileña. Y entre las muchas ventajas que esa crítica exhibía con respecto a la del resto de España, está ante todo la de su apertura europeísta, cosmopolita, renovadora. Tan radical le parece el contraste a Clarín que llega a proferir a modo de halago aquello que en verdad implicaba una riesgosa alternativa latente para su propio sentido de identidad nacional. 'Barcelona no parece España', señala, sin reconocer el inconsciente sesgo "emancipador" de su opinión:

Barcelona, que no parece España, florece en letras y en cuanto las ayuda (material o moral), seria y trabajadora, legítimamente enamorada de sí misma, para animarse con este amor propio, tan fecundo cuando es de todo un pueblo, a nuevas empresas, a más esfuerzos, a más rica y variada vida (Alas 2003 1620).

Esa extranjería es, según Clarín, la que dota a la crítica de Yxart y de sus compatriotas de un estilo de "verdadera crítica muy a la moderna" (Alas 2003 1622). Y la explicación del porqué de esa diferencia — lejos del progresismo canónico con que suele asociarse a Alas- deviene ortodoxa argumentación sobre la raza. Dice al respecto:

Sí: en estos escritores catalanes, en los de esta clase, se nota algo que parece extranjero, y que se ve en muy pocos de las otras tierras españolas, aunque sean superiores a los catalanes por otros respectos. (...) Yo, que no soy etnógrafo ni por asomos (...) no vacilo en confesar que me parece muy verosímil esta teoría de los bereberes que somos por acá, cuando considero los muchos resabios que nos quedan del clásico orientalismo que se cifra, para nosotros, en el placer de vivir echados a la bartola, cuidando tan sólo de no perder este sello nacional que tan bien nos sienta y tanto nos distingue (Alas 2003 1622) 
Clarín lamenta la potencial verdad de ser los castellanos - en sus términos - "tan negramente africanos como pretenden algunos escritores" (Alas 2003 1622), sobre todo cuando en el mismo contorno nacional gozan los catalanes de la influencia "saludable" — según sus propias palabras - de las "modernas humanidades francesas" (ibíd.). E insiste:

[E]stos críticos catalanes de ahora se diferencian de sus congéneres de Castilla, por regla general, en parecer menos... berberiscos; en recordarnos más la actividad formal e inteligente de la Europa occidental que las vaguedades poéticas del dolce far niente orientalesco (Alas 2003 1622)

La semejanza que reunía a Clarín y a Yxart en cuanto a las percepciones artísticas, era en buena parte la reacción de ambos ante la fosilización de la crítica madrileña. En este sentido, puede ratificarse un doblez sumamente interesante: por un lado, la intimidad clariniana que considera a la lengua catalana como obstáculo para la canonización de un autor español como Oller; y, por otro, sus resonantes postulados públicos reprendiendo el atraso castellano con respecto justamente a la Modernidad de las letras catalanas, es decir, con respecto al afán de novedad barcelonés, a su rigurosidad e inteligencia para la producción de valioso capital intelectual. Es más, el sentido de su afirmación acerca de que "Barcelona no parece España" puede adivinarse dividida por el filo de su propia bifrontalidad ${ }^{5}$, entre la quejumbrosa confesión del declive castellano y el reclamo nacionalista de que la apariencia en sus bases nunca significa negación de lo real. En otras palabras - y más allá de la ofuscada queja ante la caída castellana—, para Clarín es tan cierto que Barcelona pueda no parecer España, como también lo es su indudable pertenencia a la nación. Desde Alas, entonces, podría decirse que el hecho de que Barcelona no parezca España sólo destaca lo que verdaderamente es Barcelona: parte del territorio español.

Sólo a partir de esa bifrontalidad puede comprenderse su elogio sincero hacia Yxart y al mismo tiempo su decidida reacción ante los reclamos "regionalistas" que a su juicio erosionan los intereses

${ }^{5}$ Sobre la bifrontalidad de Alas entre el tradicionalismo y su genealogía liberal conviene consultar el trabajo de Joan Oleza. 
'superiores' de la nación. Yvan Lissorgues (2001) focaliza en el ataque a lo que el autor ovetense llamaba "fanatismo de campanario" y cita la idea clariniana de que "hay que tener mucho cuidado con cierta clase de regionalistas que en Cataluña, como en Galicia, como en Asturias trabajan pro domo sua; aspiran al provincialismo para ser cabeza de ratón" (19). Para Alas, lo que está en juego frente a esa ofensiva es el equilibrio de la nación. Al respecto, Lissorgues explica: "Para Clarín, ese regionalismo, que significa 'el salto atrás de la civilización, la vuelta al feudalismo', es una manifestación del egoísmo que por interés inmediato o por miopía inconsciente tiende a reducir la fuerza de la unidad nacional" (ibid.). Y es en el seno de este pensamiento que puede situarse a partir de 1896 el inicio de

[U]na aguda polémica con distintas notabilidades catalanas, como Prat de la Riba, sobre la peliaguda cuestión de la lengua catalana. Clarín no puede aceptar la base 3 de las Bases de la Manresa ("La lengua catalana será la única que con carácter oficial podrá usarse en Cataluña y en las relaciones de esta región con el poder central"); y lo dice. La polémica se entabla, con buenos modos al principio, con Prat de la Riba, a quien Clarín contesta con argumentos como el siguiente: 'El catalán está entre los dialectos que no han prevalecido. ¿Podrá negar eso el señor Prat? En ese sentido, es dialecto el catalán. Pero, ¿se le puede confundir con los dialectos no literarios que mueren por falta de cultivo $(\ldots)$ ? No (...), en este sentido el catalán es lengua porque se cultiva con esmero y amor y eficacia... pero las leyes de la realidad política conspiran contra su longevidad, contra su extensión geográfica' (Lissorgues 19).

No resulta baladí enfatizar que éste también es el momento donde empieza adquirir peso el hispanoamericanismo, entendido como "proyección exterior del nacionalismo español hacia los antiguos territorios del Imperio español en América" (García Carrión 185). Es pertinente destacarlo porque mientras de puertas adentro la península intentaba sujetar la variedad lingüística a la centralidad castellana, el americanismo propugnaba a la distancia una supuesta cercanía con las repúblicas americanas basada en un puente lingüístico que a pesar de las diferencias seguiría garantizando, supuestamente, una continuidad 
heredada. Según García Carrión, "la meta última del americanismo regeneracionista era el sostenimiento y la defensa de una identidad común" (Ibid.). Al respecto añade:

El hispanoamericanismo (...) tenía asimismo en su base un potente nacionalismo lingüístico, con la promoción del castellano como "lengua universal", nudo que hermanaba a los españoles y sudamericanos. (ibid.)

Esta bifrontalidad originada en el proyecto cultural hispánico de fin de siglo XIX tiene su correlato ejemplar en la contienda de algunos de sus intelectuales con relación al uso y jerarquización de lenguas distintas del castellano dentro mismo de la península. Clarín, de hecho, no apela tanto a la creencia de que el español es un nodo aglutinante de la identidad patria, sino que opta más bien por la reprobación de quienes quieren asociar esa función cohesiva con la variedad de lenguas a las que llama "regionales" y a las cuales suele situar por debajo de los intereses 'saludables' de la nación española'. Y es en esta línea que podría encuadrarse - casi como actitud defensiva - la persistencia en Alas de su expresa - y al parecer indoblegable - ignorancia con respecto a la lengua catalana.

Como recuerda Adolfo Sotelo Vázquez (2014), Clarín refuerza en un artículo del 7 de enero de 1896 (ya fallecido Yxart) el porqué de su tan esporádica atención a la vigorosa vida literaria de Cataluña: "se trata de su 'subjetiva situación' de no conocer a fondo la lengua catalana" (121). Y aun cuando exista ese sincerarse, su ajenidad no le impide subrayar el loable quehacer de Rusiñol, Maragall y otros. Parangonada con el idioma inglés durante su epistolario a Oller, entendida como un objeto rebelde a su entendimiento personal en la valoración crítica de sus autores señeros, el discurso crítico clariniano signa a la lengua catalana - involuntariamente, tal vez - con cierto carácter de extranjería. Resulta elocuente que estas apreciaciones de Alas sean tan cercanas en el tiempo al proceso llevado a cabo entonces por la intelectualidad barcelonesa justamente con respecto al deseo de

${ }^{6}$ Es llamativo que en esta dirección pareciera existir incluso aún más progresismo en el programa de la cátedra de Menéndez y Pelayo (1941), donde se pondera la necesidad imperiosa de considerar la variedad de lenguas para la enseñanza de la historia de la literatura. 
depurar y fijar su idioma. Explica Vicente Cacho Viu (1999) "desde mediados de 1890, hasta el comienzo de 1892 —en vísperas, por tanto, de su plena adopción del modernismo-, L'Avenç llevó a cabo una campaña lingüística, cuya importancia se ha agigantado con el paso de los años (62).

La imposición del castellano en el Principado como lengua de poder y de prestigio, "había reducido al catalán a la categoría de idioma doméstico que, si se conservaba con bastante pureza en las zonas rurales, pese a verse sometido a la inevitable dialectalización, estaba castellanizado a fondo" (62). Con Pompeu Fabra al frente, el movimiento que impulsaba la jerarquización del catalán y su normativización buscaba también, de algún modo, permitir el "renacimiento" literario de la lengua. Cacho Viu indica que "se trataba, en primer lugar, de descatellanizar al catalán, lo cual consiguió en parte eligiendo el dialecto y la pronunciación orientales, más alejados, hasta geográficamente, de la frontera lingüística invasora" (63).

Esa "batalla lingüística" sobrellevada por el empuje reivindicativo de los modernistas catalanes no es extraña, claramente, a los planteos de ciertos críticos canónicos - como los del propio Alas-, contrariados muchas veces por cierta ambigua valoración de la novedad barcelonesa, entre el aprecio de su producción y la subestimación de su lengua. Vale destacar que esa construcción crítica que hace de Barcelona una otredad para Castilla - presente tanto en Alas como en muchos de sus contemporáneos-, podía rastrearse también en la dirección inversa. De hecho, podría afirmarse que ya en el contexto de la Renaixença la necesaria vindicación de la identidad catalana irradió muchísimos testimonios de la percepción de Castilla como otredad definitoria.

Es sumamente ilustrativa, al respecto, la exposición de Stewart King (2016) sobre la construcción de Castilla como un otro dentro de la más pionera literatura catalana. Según King, el lema que titula su trabajo ("Catalonia is not Spain") persiste en los postulados recientes del Col-lectiu Emma (en respuesta a referencias particulares de la BBC en torno a Cataluña), pero viene ya de tiempos remotos. King se ocupa de rastrear sobre todo ciertos textos del siglo XIX que vengan a reforzar esta hipótesis, la que describe del siguiente modo: "I argue that the 
assertion of a specific Catalan identity has only been made posible via the simultaneous construction of certain images of the Spanish nation" (20).

Entre esas imágenes, y casi como un complemento especular de las afirmaciones clarinianas sobre el hecho de que Barcelona no "parezca" España, surgen elementos literarios propios de la Renaixença que cimientan a la vez una conciencia catalana de la otredad castellana. Si la Renaixença fue, de algún modo, la restauración del sentido de una identidad cultural de los catalanes, es lógico que la promoción de su lengua haya estado entre sus primeras ocupaciones. Por eso resulta pertinente el análisis que hace King de la oda "La Pàtria", publicada por Bonaventura-Carles Aribau en 1833. Algunos de sus versos exhiben la primigenia voluntad de relacionar la jerarquización de la lengua catalana con el sentimiento de extranjería que impulsa el olvido de la misma para un yo lírico "desterritorializado", habitante ya de una Castilla lejana:

En llemosí sonà lo meu primer vagit / quan del mugró matern la dolía llet bevia;/ en llemosí al Senyor pregava cada dia/ e càntics llemosins somiava cada nit./ Si, quan me trobe sol, parl'amb mon esperit,/ en llemosí li parli, que altra llengua no sent ${ }^{7}$ (King 24).

La construcción de Castilla como un otro de Cataluña es visible a partir del empeño por valorar la propia lengua ya desde el inicio mismo de la Renaixença y persistiendo en su denodado esfuerzo incluso hasta bien entrado el modernismo del grupo en torno a L'Avenç. Cuando Leopoldo Alas expresa su idea ambivalente de que Barcelona no parece España, no hace más que admitir el doblez mismo de ese gesto moderno y emancipado que tanto admiraba en los críticos catalanes de su contexto. King, de hecho, lee en el testimonio tardío de la novela L'hereu Noradell (de 1889) que la hybris del protagonista — capturado por su "olvido" castellano - se observa sobre todo cuando pierde su lengua, inicio definitivo de la peripecia trágica: "he no longer writes in Catalan, he only speaks and writes in Castilian" (King 26).

\footnotetext{
${ }^{7}$ Una traducción castellana sería: "En lemosín sonaron mis primeros vagidos/ al beber la dulce leche del materno pezón; / en lemosín rezaba al Señor cada día/ y cantos lemosinos soñaba cada noche / Si cuando me siento solo, le hablo a mi alma / le hablo en lemosín, que no oye otra lengua...".
} 
King concluye, con base en los textos con los cuales ejemplifica su hipótesis, que resulta imposible entender la articulación de una distinción cultural y política de Cataluña sin considerar las construcciones recurrentes que su literatura debió hacer durante todo el siglo XIX con respecto a Castilla como un otro. Cabe agregar, en este sentido, que tampoco podrán comprenderse cabalmente esas construcciones sin considerar como contrapartida posiciones bifrontes como la de Alas, capaces de admitir la otredad catalana en su ambiguo carácter como nodo diferenciado y fascinante de modernidad y, a la vez, como peligro latente contra la unidad hispánica.

En ese entorno, la amenaza para la cohesión española que implicaba la otredad de las varias lenguas peninsulares no estaba disociada del otro movimiento "invasor" contra el cual bregaba la intelectualidad castellana. El influjo francés en el modernismo americano, desde el encuadre nacionalista castellano, exhibía una galofilia que se transparentaba en la lengua y que era leída por buena parte del campo intelectual español como otro ataque directo contra la unidad trascendental de la hispanidad. De ahí que las reacciones de Clarín contra los galicismos darianos fueran estigmatizadas muchas veces como riesgos identitarios para la lengua castellana, último vehículo indiscutible de sublimación nacionalista en medio del declive imperial.

Tan notorio es el paralelismo de la reacción defensiva del castellano y de la crispación nacionalista por la pérdida de territorios coloniales, que la analogía lingüística encuentra la forma de expresarse a través de una metafórica referencia a la contienda barroca — imperial— en signar de "gongorismo" a la producción de los modernistas americanos. Lily Litvak (1990) explica al respecto: "Muchos asocian el modernismo con el culteranismo o lo califican despectivamente de gongorismo" (114). Y añade, en la misma línea: “Abundan las parodias y las sátiras del movimiento por considerar que desconoce la gramática, por su defectuosa sintaxis o su galicismo. Clarín se instituyó en defensor del castellano desde sus Paliques" (Ibid.) ${ }^{8}$. En una de sus detracciones de Rubén Darío, Alas cita al poeta nicaragüense y dictamina: "Eso no es

\footnotetext{
${ }^{8}$ Al respecto conviene tener en cuenta el análisis de José María Pozuelo Yvancos (2000) sobre las constantes de lo "genuino-popular" y de lo "foráneo-culto" en la organización del canon literario español.
} 
castellano [...] No hay Rubén, ni Simeón, ni Leví, ni Judas que hagan que eso sea español aquí ni bajo el sol de los Trópicos" (citado en Ibarra 528).

Tal como evoca Fernando Ibarra (1973) en su trabajo sobre los embates clarinianos contra Darío, fue Salvador Rueda uno de los autores a quien Alas más hostigó por su alineación con el modernismo, desplazándolo de joven promesa a corruptor del verso castellano. Asi lo afirma "Salvador Rueda, pregonero y entusiasta introductor de Darío en España, fue objeto de ataques y comentarios inmisericordes de los modernos Castillejos incapaces de adaptarse el nuevo renacimiento poético" (528). La mención de Castillejo es pertinente: remite a la vieja pugna de los Siglos de Oro, entre la poesía del castellano "puro" y transparente, y la introducción de opacidades foráneas (tan ligadas primero con las formas endecasílabas, y más adelante con la experimentación de Góngora). Por eso, es sumamente elocuente, aquella furiosa descripción de Alas que intentaba rebatir las opiniones laudatorias de Rueda:

Rubén Darío, para Rueda, es un poeta nuevo, que cincela y esculpe $\mathrm{y}$ hace todos esos primores que antes se llamaban parnasianos y ahora no hay quién sepa cómo se van a llamar... El tal Rubén Darío no es más que un versificador sin jugo propio, como hay ciento, que tiene el tic de la imitación y además escribe, por falta de estudio y sobra de presunción, sin respeto de la gramática ni de la lógica, y nunca dice nada entre dos platos. Eso es Rubén Darío, en castellano viejo (Ibarra 529).

Como puede notarse, la posición de Alas en su lapidaria amonestación de Rueda y de Darío es la de quien sostiene la autoridad del castellano viejo, concepto que en medio de esta contienda no sólo evoca una vez más la figura de Castillejo (ligado a lo "genuino" español) sino también la distancia con las modas "foráneas", las cuales en sus diversos avatares epocales vendrían a alentar un mismo espíritu de aparente disolución, desde el gongorismo al modernismo. Es así que puede arriesgarse la pregunta ¿no es este gesto defensivo contra el afrancesamiento del modernismo americano un mecanismo paralelo al de la reacción "casticista" contra el (modernismo) catalán? 
Alberto Acereda (2005) entendió el acecho antidariano como "un episodio más de la pugna entre lo castizo y lo nuevo, ante las viejas querellas de antiguos y modernos que en las letras hispánicas remonta a las luchas poéticas entre Castillejos y Garcilasos" (253). Es por esto que la sátira antimodernista resulta parienta de su contemporánea valoración de la lengua catalana como una lengua doméstica incapaz de promover la canonización de un autor español si no decide éste auto - traducirse al castellano. Lo que sin duda es sorprendente es que un intelectual de la apertura estética y política de Clarín no haya podido escapar al sesgo regresivo que despertaban en la intelectualidad castellana los modernismos americano y catalán, sobre todo en lo que respecta a sus particulares postulados lingüísticos.

En ese sentido, y para concluir, cabe confirmar la curiosa persistencia de ese hiato identitario entre el castellanocentrismo y su periferia: una brecha que lo lingüístico no hizo más que reforzar en la evidencia de cierto afán "imperial" que muchas veces España intentó sublimar culturalmente por imposición de una cohesión simbólica que empezaba a cuestionarse. En tal sentido, no pueden ser más ilustrativos de esa insistencia los ejemplos mencionados por José del Valle y Luis GabrielStheeman (2004) sobre la comunidad hispánica y el "espectáculo" vigente de la lengua. Ambos críticos recuerdan la declaración vertida por García de la Concha en El País el 6 de noviembre de 2011: "El anglicismo es una injuria al español" (242). Y sobre ello, explican:

Igual que los intelectuales españoles del XIX, recelosos de la influencia cultural francesa, advertían contra el efecto destructivo de los galicismos, así sus discípulos contemporáneos desacreditan los anglicismos que supuestamente amenazan hoy la esencia hispánica de su preciado léxico. Los préstamos del inglés se perciben como agresiones contra la dignidad del español y como amenazas a su unidad (Del Valle y Stheeman 242).

Es indudable que tales cuestiones siguen iluminando las contrariedades de una tradición que se niega a aceptar la variedad como deriva inevitable de la historicidad de la lengua y de las culturas. La polémica ortográfica que estalló en el año 2000, cuando las Academias de la lengua 
vasca, catalana y gallega protestaron contra la inclusión de topónimos locales traducidos al español, demuestra la imprescriptibilidad del asunto. La Real Academia intervino con una afirmación controvertida

Lo que tenga que decir la academia gallega, catalana y vasca, que se ocupan de esas tres lenguas, acerca de lo que decida la academia de otra lengua, es tratar de gobernarle la casa al vecino (citado en Del Valle y Stheeman 241).

Es inevitable, en el marco de los temas planteados en este trabajo, no ponderar cierta conclusión que implica destacar la continuidad notoria entre el presente y el pasado. Es decir, entre la actualidad de una subestimación del catalán como lengua meramente regional incapaz de reclamar su incidencia en el pensamiento universalizado del español, y aquella pionera invitación de Clarín a Oller para que desestimara la posibilidad de afirmar su literatura por fuera de una traducción castellana. Incluso a fuerza de dar por tierra con el acertado progresismo lingüístico que Unamuno mostró al respecto en los textos citados al inicio de este trabajo, conviene destacar que fueron casi nulos aquellos exponentes del liberalismo español capaces de escapar a la trampa del nacionalismo cultural que los embargaba en aquel contexto de crisis. Basta con dejar correr una década y hallar en el propio escritor vasco los remedos mismos de aquello que tanto había censurado en el propio Alas. Publicado el 10 de noviembre de 1907 en El Imparcial de Madrid, el artículo titulado "Las campañas catalanistas. Por la cultura" muestra un viraje de Unamuno que no hubiera dejado de estimular la ironía del propio Clarín, fallecido cinco años antes. Expresa allí que "hay un regionalismo con piel romántica y sentimental y carne de materialismo político que es un grave peligro, no ya para el patriotismo español, sino para la causa de la cultura" (Unamuno 1958b 751). Es la cultura, según Unamuno, la que corre riesgo indudable al querer arrebatársele el centro de lengua oficial al castellano. Por eso, y desdiciéndose a sí mismo, luego de subrayar el carácter "internacional" del castellano frente a las otras lenguas de la península y de recordar que el cristianismo no se propagó en el arameo de los apóstoles sino en griego, declara: 
Si Cataluña tiene un evangelio que puede levantar a España, y ojalá lo tenga, ese evangelio nos lo tiene que dar en castellano, ya que son los catalanes tan capaces de expresarse en él (...) como era capaz San Pablo, el judío, de escribir en griego (Unamuno 1958b 752)

Unamuno, aquel que había querido rectificar en Clarín el deseo afanoso de traducciones, pide finalmente a Cataluña su evangelio traducido. Entre fines de siglo XIX y la primera década del XX, el pensamiento unamuniano sobre el espíritu catalán ha dejado de privilegiar la causa metafísica y ha comenzado a considerar lo que ya Alas atisbara en su momento: la peligrosa caída de cierta hegemonía cultural castellana. Con respecto a la lengua catalana, entonces, recién en 1907 Unamuno parece caer en la cuenta de aquello que Alas ya había adivinado de manera temprana y había querido zanjar en el doblez mismo entre sus reparos íntimos y sus consejos públicos. Es decir, el escritor vasco matiza tardíamente sus primeros rodeos en torno a la exigencia trascendental de la lengua catalana como constitutiva de la identidad de sus literatos y, por ende, de España. Y termina por considerar - casi al modo clariniano- que la dialéctica ríspida entre oficialidad y lenguas locales pertenece a un plano mucho más terrenal del que había considerado previamente:

Es la causa de la cultura, es la causa del liberalismo, es el legado de los cuatro siglos de europeización, del XVI al XX, lo que corre riesgo de anegarse bajo esas reviviscencias atávicas del siglo XV que separó lo doméstico - muy digno de respeto y de cariño como tal— de lo nacional (Unamuno 1958b 757)

Es en el marco de la persistencia "nacionalista" de ese supuesto riesgo patrio - actualizado una y otra vez- que deben sopesarse las opiniones en torno al catalán vertidas por ciertos intelectuales como Clarín y Unamuno, importantes eslabones de una cadena cuya extensión paradójicamente sigue sujetando el franco entendimiento abarcador de esa identidad múltiple que parece ser, aún hoy, la hispanidad. 


\section{Referencias}

Acereda, Alberto. «El acecho antidariano. Ataques y deformaciones en torno a Rubén Darío.» Crítica Hispánica (2005): 249-270. Impreso.

Alas, Leopoldo. Epistolario, Jean-François Botrel. Oviedo: Ediciones Nobel, 2009. Impreso

Alas, Leopoldo. Obras Completas. Ed. Laureano Bonet. Vol. IV Crítica. Oviedo: Editorial Nobel, 2003. Impreso.

Cacho Viu, Vicente. «Modernismo catalán y nacionalismo cultural.» Cacho Viu, Vicente. El nacionalismo catalán como factor de modernización. Madrid: Residencia de los Estudiantes - Quaderns Crema, 1999. 49-79. Impreso.

Casanova, Pascale. La República Mundial de las Letras. Barcelona: Anagrama, 2001. Impreso .

Del Valle, José y Luis Gabriel Stheeman. «Codo con codo: la comunidad hispánica y el espectáculo de la lengua.» Del Valle, José y Luis Gabriel Stheeman. La batalla del idioma. La intelectualidad hispánica ante la lengua. Madrid: Iberoamericana, 2004. 229-263. Impreso.

Garcia Blanco, Manuel. «Clarín y Unamuno.» Garcia Blanco, Manuel. En torno a Unamuno. Madrid: Taurus, 1965. 183-208. Impreso.

García Carrión, Marta. «Cultura nacional y nacionalismo español.» Forcadell Álvarez, Carlos y Manuel Suárez Cortina. La Restauración y la República. 1874-1936. Madrid: Marcial Pons, Ediciones de Historia, 2015. 169-198. Impreso.

Ibarra, Fernando. «Clarín y Rubén Darío: historia de una incomprensión.»Hispanic Review (1973): 524-540. Impreso.

King, Stewart. «Catalonia Is Not Spain’: Images of Self and Other in Catalan Literature.» King, Stewart. A Comparative History of Literatures in the Iberian Peninsula,. Amsterdam/Philadelphia: John Benjamins Publishing Company, 2016. 20-31. Digital.

Lissorgues, Yvan. «Leopoldo Alas Clarín. Regionalismo. Nación. Europeísmo.» Revista Ínsula (2001): 18-20. Impreso.

Litvak, Lily. «La idea de la decadencia en la crítica antimodernista en España (1888-1910).» Litvak, Lily. España 1900. Modernismo, anarquismo y fin de siglo. Barcelona: Anthropos, 1990. 111-127. Impreso.

Menéndez Pelayo, Marcelino, Miguel de Unamuno y Armando Palacio Valdés. Epistolario a Clarín. Madrid: Ediciones Escorial, 1941. Impreso. 
Oleza, Juan. «Clarín y la tradición literaría.» Revista de Ciencias y Letras (2001): 22-25. Digital.

Pozuelo Yvancos, José María. «Popular/culto, genuino/foráneo: canon y teatro nacional español.» III Congreso Internacional de Teoría del Teatro: Theatralia III. Tragedia, comedia, canon. . Vigo, España: Universidad de Vigo, Facultad de Filología y Traducción, Ediciones del Área de Teoría de la Literatura, 2000. 235-260. Impreso.

Sotelo Vázquez, Adolfo. «Josep Yxart y el teatro español a finales del siglo XIX.» Sotelo Vázquez, Adolfo. De Cataluña y España. Relaciones culturales y literarias (1868-1960). Barcelona: Universidad de Barcelon, 2014. 129-150. Impreso.

Unamuno, Miguel de. «Las campañas catalanistas por la cultura.» Unamuno, Miguel de. Obras Completas . Madrid: Editorial Afrodisio Aguado, 1958b. 750-757. Impreso.

Unamuno, Miguel de. «Sobre el uso de la lengua catalana.» Unamuno, Miguel de. Obras Completas. Madrid: Afrodisio Aguado, 1958a. 723-728. Impreso.

Williams, Raymond. El teatro de Ibsen a Brecht. Barcelona: Península, 1975. Impreso . 